\title{
GUIDELINES ON CELL THERAPY
}

Andrea T. Kondo'; Andreza A. F. Ribeiro'; Fernando Barroso Duarte²; Lucia M. R. Silla³; Lucila N. Kerbauy ${ }^{1}$; Marco A. Salvino ${ }^{4}$; Nelson Hamerschlak'; Vanderson Rocha ${ }^{5,6}$; Vaneuza A. M. Funke ${ }^{7}$

1 Hospital Israelita Albert Einstein - 2 Hospital Universitário Walter Cantídio - 3 Hospital de Clínicas de Porto Alegre 4 Universidade Federal da Bahia/Hospital São Rafael-BA - 5 Hospital das Clínicas da Faculdade de Medicina Universidade de São Paulo - HCFMUSP - 6 Hospital Vila Nova Star - Rede D'or - 7 Hospital de Clinicas da Universidade Federal do Paraná

\section{INTRODUCTION}

Advanced therapy products, among the ex vivo gene (ex. CAR-T cell category) and cell therapy products (ex. NK and mesenchymal cells), cannot be used without the authorization of Anvisa, according to the laws 6360/77, 6367/77, 9782/99 and 9677/98. In this sense, places that want to use this technology must be fully regularized with the official standards and techniques. For clinical research purposes, guidelines from CEP-CONEP and Anvisa related to ethical evaluations and security and quality systems must be followed. It is also recommended that the procedures described here should be done with a multi-professional and multidisciplinary stem cell transplantation team with ability to manage complications related to these therapies.

\section{AUTOLOGOUS CAR-T CELL THERAPY}

Level of evidence 2 Grade of recommendation B

\section{DEFINITION}

The treatment consists of genetically modifying the patient's T cells to express the chimeric antigen receptor (Chimeric Antigen Receptor - CAR) specific to a particular tumor antigen, identify and eliminate malignant cells.[1] Genetic manipulation of T lymphocytes to express CAR can be carried out using viral vectors or other non-viral techniques. The owner of the product registration is responsible for the security, quality, and efficiency measures.

\section{LEUKAPHERESIS}

The production of CAR-T cells begins with the collection of peripheral blood lymphocytes. As a regis- tered product, the production must contain written documents with all the technical instructions for the collection (equipment, supplies, reagents, and other determinants of qualification of the starting material) according to the process development of the product in controlled clinical trials. It is important to check the efficiency, security, and quality. The type of collection and patient's care can vary according to the technologies undertaken and must be defined and studied during the product development phase. It is the user's responsibility and professional health to apply the agreement's requirements as the instructions for the product registration holder.

According to the current legislation, before the procedure, patients must do serological tested for HIV, hepatitis $B$, and hepatitis $C$. If the product is cryopreserved and strategies to avoid cross-contamination are not available, molecular tests must be done (NAT - nucleic acid test) for these pathogens.[2]

Literature data show that it is possible to plan or develop the product with a collection of lymphocytes from non-mobilized patients, through peripheral or central veins using equipment such as COBE Spectra and Spectra Optia (Terumo BCT, Tokyo, Japan) or Fenwal Amicus.[3]

Studies have shown the efficiency of the lymphocyte collection to program the number of volumes to be processed during the collection.

A collection efficiency can be calculated through the formula: Efficiency $(\%)=\left[\frac{\text { total product lymphocyte count } X \text { product volume }}{\text { peripheral blood lymphocyte count } X \text { processed volumes }}\right] \times 100$ 
A mean efficiency of 40 to $80 \%$ was reported in previous studies, and it is associated with lower efficiency in diseased patients, with a diagnosis of acute lymphoid leukemia (ALL) and low platelet.[4-6]

The number of volumes to be processed must be determined by clinical testing to obtain the number of lymphocyte cells established in this study, generally about 1 to $2 \times 10$ e 9 CD3 + cells in previous studies.

The recommended anticoagulation in the studies is glucose and Citrate Solution (ACD) or an association of ACD with heparin, with the collection between 0.8 to $1.5 \mathrm{ml} / \mathrm{min}$ in COBE Spectra and Spectra Optia equipment or start with the collection between $65-80 \mathrm{~mL} / \mathrm{min}$ and adjustment for blood cells and mononuclear cells of 6.8 and 1.5 respectively.[6-8]

\section{CRYOPRESERVATION}

Cryopreservation can be used in the CAR cells production in two stages: 1) freezing of mononuclear cells for subsequent processing and manipulation, 2) after the production of CAR T cells. The cryopreservation technical instructions following guidelines from Anvisa and controlled clinical trials must be available. The parameters can vary according to the technologies used. Studies must be done during the development phase of the product and must be performed following the instructions for using the product. The health care provider should know the established rules to use the product.

Previous studies evaluated the effects of cryopreservation with programmed freezing and maintenance at temperatures below $-150^{\circ} \mathrm{C}$, with no study assessing the impact of freezing in a mechanical freezer for initial product development planning.

The literature on cryopreservation of mononuclear cells follows protocols described for freezing lymphocytes and hematopoietic progenitor cells with DMSO at $10 \%$, after thawing recovering about $70 \%$ of nucleated cells, especially with $90 \%$ of CD3 cells, showing a suitable strategy for the production of CAR cells. $[9,10]$ Assessment of the impact on the transduction and the expansion of cells and the percentage of T cells and the CD4: CD8 ratio for cells' production has not been damaged by cryopreservation.[11]

Similarly, the cryopreservation of CART cells also follows the protocol of freezing lymphocytes, and the average recovery of the thawed product is at least $90 \%$. Wang $L$ and collaborators demonstrated that lower concentrations ( $2 \times 10$ e 6 cells / mL compared with $1 \times 10 e 7$ cells $/ \mathrm{mL}$ ) showed good viability.[12]
Cryopreservation in this study affected CAR T cells' cytotoxic effect; however, the product's resuspension in culture for 18 hours kept in an incubator was enough to achieve similar cytotoxicity of fresh product. These findings have not been found in other studies, which will observe slightly less viability, being corrected with more infused.[13, 14]

\section{INDICATION}

Patients with non-Hodgkin's lymphoma (NHL) and $A L L$ expressing CD19, relapsed or refractory, show unfavorable results. Although the product is based on cells with different patient and disease characteristics, this technology showed a clear benefit for high-risk patients with B-cell malignancies. Recent clinical studies show a complete response of more than $90 \%$, with CAR T cells' persistence in some patients per year 2 years after administration.[15-17] The treatment's success led to FDA approval of the first cell therapy product, Tisagenlecleucel, which consists of autologous anti-CD19 CAR-T cells for pediatric treatment patients and young adults up to 25 years old with relapsed or refractory B-cell leukemia. The approval was based on a phase 2 multicenter clinical study that showed a complete remission rate of $81 \%$ in 3 months and an overall survival rate in 12 months of $76 \%$.[18]

Axicabtagene ciloleucel was the second FDA-approved anti-CD19 CAR-T cell treatment for adult patients with refractory or relapsed aggressive non-Hodgkin's lymphoma (Diffuse Large B-Cell Lymphoma, Primary Mediastinal Large B-Cell Lymphoma, High-risk B-cell Lymphoma and Diffuse non-Hodgkin's lymphoma (B-cell transformed from follicular lymphoma). The approval was based on phase 2 multicenter clinical study results, which showed an objective response rate of $82 \%$, with a complete response of 54\% [19]. In 2018, Tisagenlecleucel was also approved for adult patients diagnosed with refractory and relapse Diffuse Large B Cell Lymphoma, high-risk B cell lymphoma, and Diffuse non-Hodgkin Lymphoma transformed from d (???) Follicular Lymphoma. Approval was based on phase 2 , an open, multicenter study with a $50 \%$ response rate (32\% complete response) in 68 patients who received a single infusion of CAR T cells. [20] In 2020, Brexucabtagene autoleucel, a product consisting of autologous anti-CD19 CAR-T cells for refractory or relapsed Mantle Cell Lymphoma, was also approved the FDA. The recognition was based on phase 2, multicenter study, which demonstrated a response in $85 \%$ with a complete response of $59 \%$ (considering the intention to treat) and overall survival of $61 \%$ in 12 months. [21] 
As well as CAR anti-CD19 for chronic lymphoid leukemia (LLC) [25], a anti-BCMA CAR for treating patients with multiple myeloma,[22-24] as well as CAR anti-CD19 for chronic lymphoid leukemia (CLL)[25], also showing encouraging results but are still awaiting FDA approval

In Brazil, the indications must be defined through controlled clinical trials to guarantee that the registered product is useful as a proposed therapeutic alternative. Besides, this type of product can only be used when registered by Anvisa, or investigational products will only be used in controlled clinical studies previously approved by the Agency and other regulatory agencies.

\section{CHEMOTHERAPY BEFORE CAR-T CELL INFUSION}

The application of chemotherapy (QT) before the infusion of adoptive immunotherapy with $T$ cells was based on several studies showing the beneficial effect of lymphodepletion with chemotherapy or radiation in immunotherapies with lymphocytes in tumors murine models. Subsequent studies in animal models and patients have demonstrated that QT before the administration of CART cells increases persistence and treatment outcomes. This benefit results from several effects, such as eliminating homeostatic cytokines, such as IL-2, IL-7, decrease in immunosuppressive cells (Tregs lymphocytes and suppressive myeloid cells), facilitating and promoting the expansion and persistence of modified $T$ cells. IL-15, for example, is an endogenous cytokine known to stimulate the proliferation and function of $\mathrm{T}$ cells and is secreted in increasing amounts after conditioning chemotherapy. The greater area under the concentration of this cytokine curve is associated with a higher proliferation of CAR-T. Therefore, the effect goes beyond lymphodepletion, and perhaps the most appropriate term is conditioning regimen and not lymphodepletion chemotherapy.[26]

Some protocols do not indicate any pre-infusion chemotherapy of CAR T cells if the WBC is less than 1000 cells / $\mu \mathrm{L}$. Most protocols suggest the use of fludarabine and cyclophosphamide, although the agents may vary according to the type of disease. Studies have shown that the addition of fludarabine to cyclophosphamide (Cy / Flu) was associated with a higher concentration of interleukin-7 (IL-7) and IL-15, with a higher level of CAR-T cells in a blood sample taken 1 month and 3 months after infusion, resulting in a better clinical result of anti-CD19 CART cells. The effect of fludarabine is multifactorial and should include a reduction in the anti-CAR response. Data show that the peak of CART cells in the first month is associated with a longer-lasting and more significant response.[27]

The regimens can be of high dosage with cyclophosphamide $60 \mathrm{mg} / \mathrm{kg}$ (total dose) and fludarabine $25 \mathrm{mg} / \mathrm{m} 2$ for 3 or 5 days or of low intensity. Studies show that low-dose regimens: cyclophosphamide of $30 \mathrm{mg} / \mathrm{kg}$ or 900 to $1500 \mathrm{mg} / \mathrm{m} 2$ of total dose with fludarabine $30 \mathrm{mg} / \mathrm{m} 2$ per day $\times 3$ days, have response rates comparable to high doses with the benefit of less toxicity. Some centers opt for bendamustine $90 \mathrm{mg} / \mathrm{m} 2$ for 2 days, mainly in the outpatient CAR T cell usage protocols.

A recent study analyzing 132 factors that could impact the overall survival and progression-free survival (SLP) of patients undergoing CAR T therapy showed that the biological effect, that is, favorable cytokine profile: increased IL-7 and MCP- 1 at day zero, is associated with higher rates of complete response and SLP. Before the infusion, chemotherapy's intensity contributes to a favorable cytokine profile, but it does not happen in all cases. Notably, the use of conditioning with intensity and higher doses of CART cells ( $2 \times 107$ $/ \mathrm{kg}$ ) is associated with more severe toxicities.[28]

It is suggested that the pre-CAR-T cell chemotherapy protocol be performed according to the registry holder's instructions.

\section{COMPLICATIONS AND CARE}

Early recognition of toxicities and immediate intervention are crucial to prevent unfavorable consequences after T-cell therapy. To achieve this goal, the training of professionals involved in patient care is essential for recognizing and managing toxicities, including doctors, nurses, pharmacists, critical care staff, and emergency medicine. The education of patients and their caregivers is also crucial.[29] It is also recommended that treatment with CAR-T cells should be carried out in bone marrow transplant units. It should be noted that the holder of the product registration must manage risks that provide for handling adverse events and long-term monitoring. The healthcare professional should use the product in accordance with the registry holder's guidelines and report related adverse events.

The most commonly found toxicities are the cytokine release syndrome and neurotoxicity described below.

\section{CYTOKINE RELEASE SYNDROME}

Cytokine release syndrome (CRS) is the most common complication after treatment with CAR-T cells. It is the result of a systemic inflammatory response caused 
when cytokines, such as interleukin 6 (IL-6), gamma interferon (IFNg), and tumor necrosis factor (TNF), are released by activated T cells or by other cells of the immune system, such as monocytes/macrophages[1]. In general, cytokine release syndrome development occurred between 1 to 10 days (median onset of 3 days) after the infusion of CAR-T cells.[30]

The CRS has a wide variety of clinical signs and symptoms such as fever, malaise and constitutional symptoms; hypotension; hypoxemia; changes in coagulation factors; target organ dysfunction, including respiratory failure, cardiovascular impairment, and renal failure; hepatic impairment.[31] After diagnosis, severity should be assessed. Several centers have used the ASTCT Consensus Grading for Cytokine Release Syndrome. Three vital signs (temperature, blood pressure, and oxygen saturation) are used to assess the classification.[32]

The treatment of SLC includes early identification through frequent monitoring, and the administration of tocilizumab can be performed from grade 2 (grade 1 if fever for more than three days without other causes)[29], in addition to symptomatic measures.[33] Tocilizumab should not be administered more than four times during the episode of CRS[29]. In cases refractory to the use of tocilizumab and SLC grade 3 or 4 , treatment with corticosteroids is indicated.[29, 33, 34].

\section{NEUROTOXICITY}

Neurotoxicity or neurotoxicity syndrome associated with immune effector cells is the second most common complication related to treatment with CAR-T cells. It can occur with the SLC or as an independent event, in this case, usually later. The average time to onset of the first neurological symptoms is 6 days (range, 1-34 days) after CAR T cells' infusion. [35] Symptom duration is generally between 2 and 9 days, although late complications may occur.[32, 35] Clinical manifestations include delirium; speech disorders; alteration in writing, impaired fine motor coordination; convulsions; and even intracranial hypertension and coma. Deterioration in writing proved to be an earlier symptom of neurotoxicity. Therefore, daily tests after the infusion of CAR T cells can assist in the identification of neurotoxicity, such as the use of the encephalopathy scale associated with immuno-effector cells (known as the ICE scale).[29, 32] The most recently used neurotoxicity graduation scale is that of the ASTCT consensus, which considers score on the ICE scale, level of consciousness, motor alteration, presence of convulsion, and elevation of intracranial pressure / cerebral edema.[32]
In the case of neurotoxicity, supportive care and diagnostic investigation with electroencephalogram to rule out electrical seizures and images of the skull to rule out cerebral edema are necessary.[34] Like SLC, neurotoxicity treatment is performed based on the severity of the disease. Tocilizumab is indicated in cases of neurotoxicity associated with SLC, but the use of tocilizumab does not appear to bring clinical benefits in isolated neurological syndrome cases. In this case, when observing neurotoxicity grade greater than or equal to 2, corticosteroids are indicated.[29, 34]

\section{NK CELLS IMMUNOTHERAPY}

Level of evidence 4 Grade of recommendation C

\subsection{NK CELLS AND HEMATOPOIETIC STEM CELL TRANSPLANTATION}

NK cells are innate large granular lymphocytes capable of lysing altered cells without previous exposition, its hallmark is the presence of KIRs able to either inhibit or activate NK cells activity. Self, normal cells are spared from NK cell lysis since KIR inhibitory receptors sense self-class I HLA antigens.[36]

NK cells play a central role in the alloSCT graft-versus-leukemia effect[37] and early recovery of NK cells following alloSCT is associated with fewer relapses and improved survival.[38] Since Perugia's group study on a T depleted haploSCT for advanced $A M L$, with superior results for those that received donor to recipient mismatched NK cells,[39] several attempts have been made to enhance the GVL effect utilizing this strategy with variable results. Such variability probably reflects differences in conditioning regimen, disease burden at transplant, graft components, and posttransplant immune suppression. Based on these observations, the adoptive transfer of in vitro activates or expanded NK cells have been tested in the SCT scenario utilizing several strategies[40-42] with variable results.

The development of PTCy-based GVHD prophylaxis [43] for haploSCT could take advantages of NK cell alloreactivity; however, cyclophosphamide appears to cause a profound depletion of NK cells soon followed by the in vivo expansion of "immature" "dysfunctional" NK cells [44] in spite of it, long term results are comparable to Match Unrelated Donor MUD SCT.[45] In an attempt to augment the GVL effect in the PTCy-Haplo SCT, peripheral blood mononuclear cells expanded with membrane-bound IL-21 antigen-presenting cells (mbll-21),[46] administered in day $-2,+7$, and +28 after transplant is presently been tested with encouraging results.[47] 


\section{NK CELLS ADOPTIVE IMMUNOTHERAPY OUTSIDE SCT SCENARIO}

Based on the above-mentioned studies, NK-cell adoptive immunotherapy (NK-Al) could be an option for obtaining a "graft-versus-leukemia" effect in the absence of alloSCT, particularly for myeloid leukemias. Haploidentical NK-cell infusions in patients with relapsed or refractory AML have been shown to be well tolerated, with remission reported in five of 19 patients [48] and four of nine patients [49] when given after cyclophosphamide and fludarabine, and in four of six patients when administered after two cycles of intensive chemotherapy.[50] In a recent study, haploidentical NK-cell infusions followed by rhIL-15 administration, remission was achieved in $35 \%$ of patients with refractory acute myeloid leukemia; however, SC dosing of rhlL-15 after lymphodepletion prolongs drug exposure leading to cytokine release syndrome and neurotoxicity in $56 \%$ of patients [51]

In a recent Phase 1 trial, we were able to in vitro expand NK cells co-culturing with mbll-21 from all donors, and the response was observed in $78.6 \%$ with $50 \%$ of CR. NK cells infusions were safe, and dose limit toxicity or cytokine released syndrome were not observed (submitted manuscript). Of interest, we documented CNS responses suggesting this same strategy i.e. systemic infusion of mblL-21 expanded/activated NK cells could be used for CNS tumors. It also important to point out that the IV infusion of such an active NK cell, not only display an impressive anti-tumor activity, but also dismiss the need for the utilization of post infusion Interleukin administration. [52]

Although still in experimental, the effectivity and the lack of toxicity particularly when utilized without the systemic administration of Interleukin, might suggest that NK cell adoptive immunotherapy is a promising alternative, particularly for elderly patients unfit for SCT or for those without a donor.

We recommend the adoptive NK cells treatment only in clinical trials, and it is the sponsor and the researcher's responsibility to verify the safety, quality and efficiency, and the requirements and post-treatment monitoring. Furthermore, concerning manufacturing, production equipment, such as bioreactor or automated platforms, needs to be linked to a research product in an approved clinical trial in Brazil or a registered product.

\section{MESENCHYMAL CELLS}

Mesenchymal stem cells (MSC) are multipotent cells from the bone marrow or other hematopoietic tissues (umbilical cord, fetal liver), which can differen- tiate in vivo and in vitro in tissues of mesenchymal origin (cartilage, muscles, fat). Besides, these cells support the growth and differentiation of hematopoietic progenitor cells in the bone marrow microenvironment. In animal models, these cells are capable of leading to the engraftment of hematopoietic cells. In in vitro joint culture experiments, mesenchymal stem cells (MSC) suppress the proliferation of activated lymphocytes in a dose-dependent manner and without restriction on HLA antigens.[53-55]

\section{ACUTE GRAFT-VERSUS-HOST-DISEASE (A-GVHD)}

\section{Level of evidence 1 Grade of recommendation A}

Due to its immunomodulatory profile, several researchers have reported their experience with the use of mesenchymal stem cells for the treatment of refractory a-GVHD.[56-58]

Le Blanc et al. published in 2004 a case report of a nine-year-old boy with severe GVHD-a refractory to various treatments and who achieved remission with the infusion of mesenchymal cells from his mother.[56]

More recently, a phase II study by the same author reported the use of infusion of mesenchymal stem cells to treat severe refractory GVHD. In this study, 55 patients with severe GVHD, resistant to corticosteroids were studied. The authors infused a median dose of MSC of $1.4 \times 106$ per kg of weight. Twenty-seven patients received one dose, 22 patients received two doses and six patients received three to five doses of cells obtained from their donors with varying degrees of compatibility and kinship. Thirty patients obtained a complete response and nine showed improvement. Importantly, no patient experienced adverse events to or immediately after the infusion. Three patients had relapse and one patient had acute myeloid leukemia again, originating from the patient himself. Patients who had a complete response had lower transplant-related mortality one year after the infusion when compared to those with partial or no response (11 [37\%] of 30 vs 18 [72\%] of $25 ; \mathrm{p}=0.002$ ) and best overall 2-year survival after HSCT (16 [53\%] of 30 vs four [16\%] of $25 ; p=0.018$ ). These responses were not related to the type of donor or HLA compatibility [57]

Von Bonin et al published in 2009 their experience with the use of mesenchymal cells in 13 patients, of which only two obtained a complete response with the initial infusion. Eleven patients received another 
immunosuppressive treatment associated with new infusions of mesenchymal cells and of these, five (45\%) responded. The reported survival was 31\%.[58]

Martin et al recently reported their experience with Prochymal R (Osiris Therapeutics, Inc., Columbia, $M D)$, a preparation of human mesenchymal cells expanded by culture and from unrelated donors, formulated for intravenous injection. One hundred and sixty-three patients received the product and 81 patients received placebo as treatment for refractory GVHD. The group treated with Prochymal R obtained an overall response of $82 \%$, but the difference in relation to the control group was found only in patients with a-GVHD-involving the liver $(76 \%$ x 47\%, OR 3.6 [95\% Cl 1.1- 11.2], $\mathrm{p}<0.05)$ and intestine $(82 \% \times 68 \%$, OR 2.2 [95\% Cl 1.1-4.4], p <0.05).[59]

Kebriaei et al reported in 2009 a phase II study with 31 patients divided into two groups according to the dose of mesenchymal cells $(2 \times 106$ or $8 \times 106$ MSC $/ \mathrm{Kg})$. ProchymalR was used. The difference of this study is that the patients received this preparation as an initial treatment for patients with a-GVHD in conjunction with corticosteroids. Ninety-four percent of patients responded, $77 \%$ complete and $16 \%$ partial. No toxicities to the infusion or ectopic tissue formation were observed.[60]

In the phase III study with this same product, a total of 260 patients, from six months to 70 years of age, were evaluated from August 2006 to May 2009 and randomized 2: 1 to receive eight intravenous infusions of remestemcel-L or placebo for four weeks in addition to the Institution's standard second-line therapy. Four additional infusions were indicated for patients with incomplete response by day 28 . Safety and efficacy were assessed at 180 days of follow-up and the primary objective was the complete durable response (DCR), defined as complete resolution of the signs of GVHD by up to 28 days after treatment. The primary objective was not achieved in the intention to treat analysis ( $35 \% \times 30 \% ; P=0.42)$. In a post hoc analysis, patients with hepatic involvement who received at least one infusion of remestemcel-L had a higher DCR, and higher rates of complete or partial response when compared to those who received placebo ( $29 \% \times 5 \%$; $P=.047)$. Among high-risk patients (aGVHD grades $C$ and D), remestemcel-L also demonstrated a higher global response on day 28 (58\% $\times 37 \% ; P=0.03)$. In addition, pediatric patients had a better overall response with SCD than those who received placebo ( $64 \%$ versus $23 \% ; P=.05$ ). [4]

Early intervention is important in the treatment of GVHD-a since there is a circular cascade of cell activation and production of inflammatory cytokines.
[61]. It is reasonable to hypothesize that the sooner immunomodulation is offered, the greater its effectiveness since fewer clones will be activated and less cytokines will be produced. Accordingly, the Kebriaei [60] study found a high response rate, with no associated toxicity.

Dotolli GM et al. reported results from 46 patients treated with infusion of mesenchymal cells (MSC) for rescue of steroid-refractory Grade II to IV a-GVHD (78\% grade IV). Patients received a median cumulative dose of MSC of $6.81 \times 106 / \mathrm{kg}(0.98-29.78 \times 106$ $/ \mathrm{kg}$ ) over a median of three infusions (1-7). The median time between the diagnosis of GVHD-a and the first infusion of MSC was 25.5 days (6-153). Half of the patients showed clinical improvement (23/46). Of these, three patients obtained a complete response (13\%), 14 (61\%) partial response and six (26\%) transient partial response. The estimated probability of two-year survival was $17.4 \%$. Only two patients (4.3\%) had transient adverse events (nausea, vomiting and blurred vision) during the infusion. No patient had a serious adverse event. These results suggest that this therapeutic modality is safe and should be considered for the Treatment of steroid-refractory GVHD, especially in countries where second-line agents are less accessible.[62]

A recent meta-analysis did not find, however, a clear beneficial effect of the use of mesenchymal cells to treat a-GVHD and therefore, further randomized studies are needed to better establish the role of this therapeutic modality.[63] Furthermore, it is advisable that the treatment using a product based on mesenchymal cells for GVHD-a be carried out after authorization by Brazilian regulatory agencies such as Anvisa. The registry holder is fully responsible for proving safety, quality, effectiveness, and the requirements and post-treatment monitoring.

\section{A. CHRONIC GRAFT-VERSUS-HOST-DISEASE (C-GVHD)}

Level of evidence 4 Grade of recommendation C

Like a-GVHD, c-GVHD is an important and frequent complication of allogeneic hematopoietic stem cell transplantation, and one of the biggest causes of morbidity, mortality and impact on the quality of life of transplant patients.[64] As MSC are involved in tissue repair and modulation of immune responses in vivo and in vitro, its use for C- GVHD has also been evaluated by different researchers with surprising initial results.[65]

Weng JY and colleagues recently reported the results of the treatment of 19 patients with refractory 
chronic graft disease treated with infusions of mesenchymal cells from April 2005 to October 2008. There was a response in $73.7 \%$ of patients and 10 of 19 patients could reduce by more than $50 \%$ or discontinue immunosuppressants altogether. The authors conclude that the treatment was effective in rescuing these patients.[66]

Zhang LS and collaborators [67] also reported their results of infusing mesenchymal cells from identical HLA donors, haploidentical donors or volunteers in 12 patients with refractory GVHD. There were no side effects related to the infusions, the global response was $75 \%$ (9/12) and complete resolutions were observed in patients with cutaneous (3/12), pulmonary $(1 / 3)$, articular (1/5) involvement, hepatic (3/10), oral cavity (4/12) and ocular (2/7), regardless of the type of donor used. The median follow-up of this study was 1152 (795-1914) days, the leukemia-free survival was $91.7 \%(11 / 12)$ and the overall survival $75 \%$ (9/12). The CD4 / CD8 ratio and the proportion of regulatory $T$ cells were significantly higher than before treatment. The verification of a complete response in patients with bronchiolitis obliterans (pulmonary GVHD) is consistent with studies that demonstrate the usefulness of these cells in various inflammatory diseases of the lungs, and even in idiopathic pulmonary fibrosis.[68]

Weng $J$ et al. reported their results of infusing these cells in 22 patients with severe ocular sicca syndrome secondary to chronic graft disease, with improvement in symptoms in $55.54 \%$ of treated patients.[69] These results imply the need for further clinical studies to assess the potential of using this procedure in intractable and lethal situations, as is the case of refractory chronic graft disease. The use of products based on refractory $\mathrm{DECH}-\mathrm{c}$ mesenchymal cells will only be carried out in controlled clinical studies previously approved by Anvisa and other regulatory agencies.

\section{ACKNOWLEDGMENT}

We thank Anvisa and the Blood, Tissues, Cells, and Organs-GSTCO Management team for their collaboration in the discussions for preparing this document.

\section{REFERENCES}

1. June, C.H. and M. Sadelain, Chimeric Antigen Receptor Therapy. N Engl J Med, v.379, n.1, p.64-73. 2018.

2. Resolução de Diretoria Colegiada no 214 de 7 de fevereiro de 2018 e Resolução de Diretoria Colegiada no 20, de 10 de abril de 2014, D.C.d.A.N.d.V. Sanitária, Editor.: Diário da União n 36 e Diário da União $n^{\circ} 20$.

3. Tuazon, S.A., et al., Factors affecting lymphocyte collection efficiency for the manufacture of chimeric antigen receptor $T$ cells in adults with B-cell malignancies. Transfusion, v.59, n.5, p.1773-1780.

4. Kebriaei, P., et al., A Phase 3 Randomized Study of Remestemcel- $L$ versus Placebo Added to Second-Line Therapy in Patients with Steroid-Refractory Acute Graft-versus-Host Disease. Biol Blood Marrow Transplant, v.26, n.5, p.835844, 2020.

5. Allen, E.S., et al., Autologous lymphapheresis for the production of chimeric antigen receptor $T$ cells. Transfusion, v.57, n.5, p. 1133-1141, 2017.

6. Howell, C., et al., Guideline on the clinical use of apheresis procedures for the treatment of patients and collection of cellular therapy products. British Committee for Standards in Haematology. Transfus Med, v. 25, n. 2, p. 57-78, 2015.

7. Lee, S.N., et al., Comparison of Two Apheresis Systems of COBE and Optia for Autologous Peripheral Blood Stem Cell Collection. Ann Lab Med, v.37, n. 4, p. 327-330, 2017.

8. Karafin, M.S., et al., Evaluation of the Spectra Optia apheresis system for mononuclear cell (MNC) collection in G-CSF mobilized and nonmobilized healthy donors: results of a multicenter study. $J$ Clin Apher, v.29, n.5, p. 273-280, 2014.

9. Panch, S.R., et al., Effect of Cryopreservation on Autologous Chimeric Antigen Receptor T Cell Characteristics. Mol Ther, v.27, n.7, p.1275-1285, 2019.

10. Tyagarajan, S., et al., Autologous cryopreserved leukapheresis cellular material for chimeric antigen receptor-T cell manufacture. Cytotherapy, v.21, n.12, p. 1198-1205, 2019.

11. Hanley, P.J., Fresh versus Frozen: Effects of Cryopreservation on CAR T Cells. Mol Ther, v.27, n.7, p.1213-1214, 2019. 
12. Wang, L., et al., Improvement of in vitro potency assays by a resting step for clinical-grade chimeric antigen receptor engineered T cells. Cytotherapy, v.21, n.5, p. 566-578, 2019.

13.Lee, S.Y., et al., Preclinical Optimization of a CD20-specific Chimeric Antigen Receptor Vector and Culture Conditions. J Immunother, v.83, p.40-47, 2018.

14. Xu, H., et al., Effects of cryopreservation on chimeric antigen receptor $T$ cell functions. Cryobiology, v.83, p.40-47, 2018.

15. Lee, D.W., et al., T cells expressing CD19 chimeric antigen receptors for acute lymphoblastic leukaemia in children and young adults: a phase 1 dose-escalation trial. Lancet, v.385, n.9967, p. 517-528, 2015.

16.Tasian, S.K. and R.A. Gardner, CD19-redirected chimeric antigen receptor-modified $T$ cells: a promising immunotherapy for children and adults with B-cell acute lymphoblastic leukemia (ALL). Ther Adv Hematol, v.6, n.5, p. 228-241, 2015.

17.Gardner, R.A., et al., Intent-to-treat leukemia remission by CD19 CAR T cells of defined formulation and dose in children and young adults. Blood, v.129, n.25, p. 3322, 3331, 2017.

18.Maude, S.L., et al., Tisagenlecleucel in Children and Young Adults with B-Cell Lymphoblastic Leukemia. N Engl J Med, v.378, n.5, p. 439-448. 2018.

19.Neelapu, S.S., et al., Axicabtagene Ciloleucel CAR T-Cell Therapy in Refractory Large B-Cell Lymphoma. NEngl J Med, v.377, n.26, p. 2531-2544.

20.Schuster, S.J., et al., Chimeric Antigen Receptor T Cells in Refractory B-Cell Lymphomas. N Engl J Med, v.377, n.26, p.2545-2554.

21.Wang, M., et al., KTE-X19 CAR T-Cell Therapy in Relapsed or Refractory Mantle-Cell Lymphoma. NEng/ J Med, v.382, n.14, p. 1331-1342, 2020.

22.Raje, N., et al., Anti-BCMA CAR T-Cell Therapy bb2121 in Relapsed or Refractory Multiple Myeloma. N Engl J Med, v.380. n. 18, p. 1726-1737, 2019.

23.Cohen, A.D., et al., B cell maturation antigen-specific CAR T cells are clinically active in multiple myeloma. J Clin Invest, v. 129, .6, p. 2210-2221, 2019.

24.Mikkilineni, L. and J.N. Kochenderfer, CAR T cell therapies for patients with multiple myeloma. Nat Rev Clin Oncol, 2020.

25.Abramson, J.S., et al., Lisocabtagene maraleucel for patients with relapsed or refractory large B-cell lymphomas (TRANSCEND NHL 001): a multicentre seamless design study. Lancet, v. 396, n. 10254, p. 839-852, 2020.

26.Kochenderfer, J.N., et al., Lymphoma Remissions Caused by Anti-CD19 Chimeric Antigen Receptor T Cells Are Associated With High Serum Interleukin-15 Levels. J Clin Oncol, v. 35, n.16, p p. 1803-1813, 2017.

27.Turtle, C.J., et al., Immunotherapy of non-Hodgkin's lymphoma with a defined ratio of CD8+ and CD4+ CD19-specific chimeric antigen receptor-modified T cells. Sci Transl Med, v.8, n.355, p.355

28. Hirayama, A.V., et al., The response to lymphodepletion impacts PFS in patients with aggressive non-Hodgkin lymphoma treated with CD19 CAR T cells. Blood, v.133, n.17, p. 1876-1887, 2019.

29. Yakoub-Agha, l., et al., Management of adults and children undergoing chimeric antigen receptor T-cell therapy: best practice recommendations of the European Society for Blood and Marrow Transplantation (EBMT) and the Joint Accreditation Committee of ISCT and EBMT (JACIE). Haematologica, v.105, n.2, p. 297-316, 2020

30.Gauthier, J. and C.J. Turtle, Insights into cytokine release syndrome and neurotoxicity after CD19-specific CAR-T cell therapy. Curr Res Transl Med, v.66, n.2, p.50-52, 2018.

31.Brudno, J.N. and J.N. Kochenderfer, Toxicities of chimeric antigen receptor $T$ cells: recognition and management. Blood, v.127, n.26,p. 3321-30, 2016.

32.Lee, D.W., et al., ASTCT Consensus Grading for Cytokine Release Syndrome and Neurologic Toxicity Associated with Immune Effector Cells. Biol Blood Marrow Transplant, v.25, n.4, p. 625638, 2019.

33.Yanez, L., et al., How I treat adverse effects of CAR-T cell therapy. ESMO Open, 2020. 4(Suppl 4).

34.Neelapu, S.S., Managing the toxicities of CAR T-cell therapy. Hematol Oncol, 2019. 37 Suppl 1: p. 48-52. 
35.Rubin, D.B., et al., Neurological toxicities associated with chimeric antigen receptor $\mathrm{T}$-cell therapy. Brain, v.142,n.5, p. 1334-1348, 2019.

36.Caligiuri, M.A., Human natural killer cells. Blood, v. 112, n.3, p. 461-9, 2008.

37.Dickinson, A.M., et al., Graft-versus-Leukemia Effect Following Hematopoietic Stem Cell Transplantation for Leukemia. Front Immunol, v.8, p.496, 2017.

38. Hattori, N., et al., Status of Natural Killer Cell Recovery in Day 21 Bone Marrow after Allogeneic Hematopoietic Stem Cell Transplantation Predicts Clinical Outcome. Biol Blood Marrow Transplant, v.24, n.9, p. 1841-1847, 2018.

39.Ruggeri, L., et al., Effectiveness of donor natural killer cell alloreactivity in mismatched hematopoietic transplants. Science, v. 295, n.5562, p.2097-100, 2002.

40.Lee, D.A., et al., Haploidentical Natural Killer Cells Infused before Allogeneic Stem Cell Transplantation for Myeloid Malignancies: A Phase I Trial. Biol Blood Marrow Transplant, v.22, n.7, p. 1290-1298, 2016.

41.Benjamin, J.E., S. Gill, and R.S. Negrin, Biology and clinical effects of natural killer cells in allogeneic transplantation. Curr Opin Oncol v.22, n.2, p.130-7, 2010.

42.Tsirigotis, P., A. Shimoni, and A. Nagler, The expanding horizon of immunotherapy in the treatment of malignant disorders: allogeneic hematopoietic stem cell transplantation and beyond. Ann Med, v.46, n.6, p.384-96, 2014.

43.Luznik, L., et al., HLA-haploidentical bone marrow transplantation for hematologic malignancies using nonmyeloablative conditioning and high-dose, posttransplantation cyclophosphamide. Biol Blood Marrow Transplant, v.14, n.6, p.641-50, 2008.

44.Russo, A., et al., NK cell recovery after haploidentical HSCT with posttransplant cyclophosphamide: dynamics and clinical implications. Blood, v.131, n.2, p.247-262, 2018.

45.Ciurea, S.O., et al., Haploidentical transplant with posttransplant cyclophosphamide vs matched unrelated donor transplant for acute myeloid leukemia. Blood, v.126, n.8, p.1033-40, 2015.

46.Denman, C.J., et al., Membrane-bound IL-21 promotes sustained ex vivo proliferation of human natural killer cells. PLoS One, v.7, n.1, p. 30264, 2012.

47.Ciurea, S.O., et al., Phase 1 clinical trial using mblL21 ex vivo-expanded donor-derived NK cells after haploidentical transplantation. Blood, v.130, n.16, p.1857-1868, 2017.

48.Miller, J.S., et al., Successful adoptive transfer and in vivo expansion of human haploidentical NK cells in patients with cancer. Blood, v.105, n.8, p.3051-7, 2005.

49.Romee, R., et al., Cytokine-induced memory-like natural killer cells exhibit enhanced responses against myeloid leukemia. Sci Transl Med, v.8, n.357, p.357ra 123, 2016.

50.Vela, M., et al., Haploidentical IL-15/41BBL activated and expanded natural killer cell infusion therapy after salvage chemotherapy in children with relapsed and refractory leukemia. Cancer Lett, v. 422, p.107-117, 2018.

51.Cooley, S., et al., First-in-human trial of rhlL-15 and haploidentical natural killer cell therapy for advanced acute myeloid leukemia. Blood Adv, v. 3, n.13, p. 1970-1980. 2019.

52.Lucia Silla, V.V., et al. Phase I Study of Adoptive Transfer of Haploidentical Expanded NK Cells, in 46th Annual Meeting of the EBMT. 2020, Lucia Silla: Amsterdam.

53.Klyushnenkova, E., et al., T cell responses to allogeneic human mesenchymal stem cells: immunogenicity, tolerance, and suppression.J Biomed Sci, v.12, n.1, p.47-57, 2005.

54.Le Blanc, K., et al., Mesenchymal stem cells inhibit and stimulate mixed lymphocyte cultures and mitogenic responses independently of the major histocompatibility complex. Scand J Immunol, v. 57, n.1, p.11-20, 2003.

55.Bartholomew, A., et al., Mesenchymal stem cells suppress lymphocyte proliferation in vitro and prolong skin graft survival in vivo. Exp Hematol, v.30, n.1, p.42-8, 2002.

56.Le Blanc, K., et al., Treatment of severe acute graft-versus-host disease with third party haploidentical mesenchymal stem cells. Lancet, v, 363, n.9419, p. 1439-41, 2004.

57.Le Blanc, K., et al., Mesenchymal stem cells for treatment of steroid-resistant, severe, acute graft-versus-host disease: a phase II study. Lancet, v.371, n.9624, p. 1579-86, 2008. 
58.von Bonin, M., et al., Treatment of refractory acute GVHD with third-party MSC expanded in platelet lysate-containing medium. Bone Marrow Transplant, v.43, n.3, p. 245-51, 2009.

59.Martin, P.J., et al., Prochymal Improves Response Rates In Patients With Steroid-Refractory Acute Graft Versus Host Disease (SR-GVHD) Involving The Liver And Gut: Results Of A Randomized, Placebo-Controlled, Multicenter Phase III Trial In GVHD. Biology of Blood and Marrow Transplantation, v.16, n.2, p.S169-S170, 2010.

60.Kebriaei, P., et al., Adult human mesenchymal stem cells added to corticosteroid therapy for the treatment of acute graft-versus-host disease. Biol Blood Marrow Transplant, v.15, n.7, p.804-11, 2009.

61.Willenbacher, W., et al., Treatment of steroid refractory acute and chronic graft-versus-host disease with daclizumab. Br J Haematol, v. 112, n.3, p.820-3, 2001.

62.Dotoli, G.M., et al., Mesenchymal stromal cell infusion to treat steroid-refractory acute GvHD III/ IV after hematopoietic stem cell transplantation. Bone Marrow Transplant, v.52, n.6, p.859-862, 2007.

63.Fisher, S.A., et al., Mesenchymal stromal cells as treatment or prophylaxis for acute or chron- ic graft-versus-host disease in haematopoietic stem cell transplant (HSCT) recipients with a haematological condition. Cochrane Database Syst Rev , v.125, n.4, p. 606-15, 2015.

64.Flowers, M.E. and P.J. Martin, How we treat chronic graft-versus-host disease. Blood, v.125, n.4, p. 606-15, 2015.

65.Herrmann, R., et al., Mesenchymal stromal cell therapy for steroid-refractory acute and chronic graft versus host disease: a phase 1 study. Int $J$ Hematol, v.95, n.2, p.182-8,2012.

66.Weng, J.Y., et al., Mesenchymal stem cell as salvage treatment for refractory chronic GVHD. Bone Marrow Transplant, 45(12): v.45, n. 12, p. 1732-40, 2010.

67.Iyer, S.S., C. Co, and M. Rojas, Mesenchymal stem cells and inflammatory lung diseases. Panminerva Med, v.51, n.1. p.5-16, 2009.

68.Zhang, L.S., et al., Mesenchymal stem cells for treatment of steroid-resistant chronic graft-versus-host disease]. Zhonghua Nei Ke Za Zhi, v.48, n.7, p.542-6, 2009.

69.Weng, J., et al., Mesenchymal stromal cells treatment attenuates dry eye in patients with chronic graft-versus-host disease. Mol Ther, v. 20, n.12, p. 2347-54, 2012. 